\title{
Micropropagação e conservação de Macrosyphonia velame (St. Hil.) Muell. Arg. em banco de germoplasma in vitro
}

\author{
Micropropagation and conservation of Macrosyphonia velame (St. Hil.) \\ Muell. Arg. in vitro germoplasm bank
}

\section{Letícia Maria Martins ${ }^{\mathrm{I}}$ Ana Maria Soares Pereira ${ }^{\mathrm{II}}$ Suzelei de Castro França ${ }^{\mathrm{II}}$ Bianca Waléria Bertoni ${ }^{{ }^{*}}$}

\section{RESUMO}

\begin{abstract}
A Macrosyphonia velame é uma planta medicinal do Cerrado, pertencente à família Apocynaceae, e conhecida popularmente como velame branco. Extratos de raizes de velame são utilizados pela população como depurativo e anti-sifilítico. Este trabalho teve como objetivo desenvolver o protocolo de micropropagação de M. velame, com vistas à conservação da espécie em Banco do Germoplasma in vitro. Sementes foram coletadas nos municípios de Sacramento, Tapira e Araxá, MG, e utilizadas como fonte de explantes. Segmentos nodais de plântulas axênicas foram transferidos para meio MS/2 suplementado com BAP, Cinetina, 2ip e TDZ em diferentes concentrações $\left(0,25 ; 5,0\right.$ e $\left.1,0 \mathrm{mg} \mathrm{L}^{-1}\right)$. Para o enraizamento, brotações com $2 \mathrm{~cm}$ de altura foram transferidas para meios MS/2 suplementado com 1,0; 5,0; e 10,0mg $L^{-1}$ de IBA ou ANA e cultivadas por 5,10 e 30 dias, sendo em seguida subcultivadas em MS/2 por mais trinta dias e só então avaliadas quanto à formação de raízes. Na aclimatização e enraizamento ex vitro, foram utilizados substratos Plantmax ${ }^{\circledR}$, areia e solo individualmente ou em combinações (1:1) de areia/Plantmax ${ }^{\circledR}$; areia/solo; Plantmax ${ }^{\circledast} /$ solo. Para o estabelecimento do Banco de Germoplasma, brotações com $3,5 \mathrm{~cm}$ foram transferidas para meio MS/2 suplementado com $2 \%$ de sacarose $+4 \%$ de manitol ou sorbitol; $2 \%$ de sacarose $+4 \%$ de manitol ou sorbitol $+2 \mathrm{mg} \mathrm{L}^{-1}$ de pantotenato de cálcio; $2 \%$ de sacarose + $4 \%$ de manitol ou sorbitol $+2 m g L^{-1}$ de espermidina. A porcentagem de germinação in vitro foi baixa, $33 \%, 4 \%$ e $2 \%$ das sementes coletadas em Araxá, Tapira e Sacramento, respectivamente. $O$ meio $M S / 2$ sem adição de citocinina promoveu a proliferação de brotos (4,0 por gema), elongação $(5,2 \mathrm{~cm})$, número de gemas $(8,6)$ e reduziu vitrificação $(4 \%)$. Em relação aos substratos testados, as plântulas se desenvolveram melhor no Plantmax ${ }^{\circledast}$, sendo que $40 \%$ das plântulas sobreviveram e a maioria apresentou formação de raízes. Plântulas cultivadas por três meses em meio de cultura
\end{abstract}

$M S / 2+2 \%$ de sacarose $+4 \%$ de manitol $+2 m g L^{-1}$ de pantotenato de cálcio, sob condições de Banco de Germoplasma, apresentaram $40 \%$ de sobrevivência.

Palavras-chave: Apocinaceae, cultura de tecidos, planta medicinal, Cerrado, velame.

\section{ABSTRACT}

Root extracts of Macrosyphonia velame an Apocynaceae native of Brazilian Cerrado, known as white velame have been popularly used as depurative and antisyphilitic agent. The aim of the present research was to develop a micropropagation protocol for the in vitro conservation of M. velame in a germplasm bank. Seeds of velame collected in Sacramento, Tapira and Araxá, MG, Brazil, were used as initial explants. Nodal segments from axenic plantlets were inoculated on MS/2 medium supplemented with different concentrations (0.25, 5.0 and 1.0mg $\left.L^{-1}\right)$ of BAP; kinetin; $2 i P$ or TDZ. For in vitro rooting, plantlets $(2 \mathrm{~cm}$ high) were inoculated on $M S / 2$ medium supplemented with IBA or NAA (1.0, 5.0, and 10.0mg $\left.L^{-1}\right)$, maintained for 5, 10 and 30 days and sub-cultured to MS/ 2 medium for an additional thirty days before evaluating rooting. For acclimatization and ex vitro rooting plantlets were transplanted into Styrofoam boxes containing either Plantmax $^{\circledast}$, sand and soil one by one or in combinations (1:1) of sand/Plantmax ${ }^{\circledast} ;$ sand/soil; Plantmax ${ }^{\circledast} /$ soil. For the in vitro conservation of M. velame in germplasm bank plantlets $(3.5 \mathrm{~cm}$ high) were inoculated on MS/2 medium supplemented with either $2 \%$ sucrose $+4 \%$ of mannitol or sorbitol; $2 \%$ sucrose + $4 \%$ mannitol or sorbitol $+2 \mathrm{mg} \mathrm{L}^{-1}$ calcium pantothenate; $2 \%$ of sucrose $+4 \%$ of mannitol or sorbitol $+2 m g L^{-1}$ spermidine. The proportion of seed germination was considered low, 33\%, $4 \%$ and $2 \%$ for seeds collected in Araxá, Tapira and Sacramento respectively. Explants cultured on MS/2 medium without addition of cytokinin showed enhanced height $(5.2 \mathrm{~cm})$,

IPrograma de Pós-graduação em Biotecnologia, Universidade de Ribeirão Preto (UNAERP), Ribeirão Preto, SP, Brasil.

"Unidade de Biotecnologia de Plantas Medicinais, UNAERP, 14096-900, Ribeirão Preto, SP, Brasil. E-mail:

bbertoni@unaerp.br*Autor para correspondência. 
increased number of buds (8.6), proliferation of 4 shoots per bud and minimal (4\%) proportion of vitrification. Plantlets acclimatized ex vitro developed better in Plantmax ${ }^{\circledR}$ substrate, most plantlets presented root formation and survival reached $40 \%$. M. velame plantlets cultured for three months on MS/2 added with $2 \%$ sucrose $+4 \%$ mannitol $+2 \mathrm{mg} \mathrm{L}^{-1}$ of calcium pantothenate, under germoplasma bank conditions presented $40 \%$ of survival.

Key words: Apocinaceae, tissue culture, medicinal plant, Cerrado, velame.

\section{INTRODUÇÃO}

O Cerrado é o segundo maior bioma brasileiro e apresenta características peculiares por sua constituição em mosaicos, com vegetação que varia desde campos abertos até formações florestais. A riqueza de espécies, tanto da flora quanto da fauna, é expressiva, representando cerca de $30 \%$ da biodiversidade brasileira (AGUIAR \& CAMARGO, 2004).

Este bioma apresenta uma flora medicinal riquíssima e vem sofrendo um histórico processo de degradação, principalmente pela produção de monoculturas, sobretudo de plantas anuais como soja, arroz e milho que ocupam áreas extensas, comprometendo a heterogeneidade e riqueza florística (ALMEIDA et al., 1998). Com a expansão da fronteira agrícola, a fauna e muitas espécies vegetais medicinais bem como o conhecimento a elas associado vêm desaparecendo, o que contribuiu para que o Cerrado se tornasse um dos 25 hotspots mundiais (MEYERS et. al., 2000).

Segundo FACHIM \& GUARIM (1995), plantas como velame (Macrosyphonia velame), verga teso (Anemopaegma arvense), barbatimão (Stryphnodendron adstringens) e mangava brava (Lafoensia pacari) estão enquadradas na categoria de espécies vulneráveis. Essa situação é agravada pelo fato de essas plantas conterem seus princípios ativos nas raízes, xilopódios e entrecasca, cuja retirada dos órgãos ou parte da planta compromete a sobrevivência da espécie.

Macrosyphonia velame é uma espécie medicinal nativa do Cerrado, pertencente à família Apocynaceae. É conhecida popularmente como velame-branco, velame, babado, barbasco, flor-debarbeiro e jalapa-branca. A raizé amplamente utilizada pela população como antiinflamatório, depurativo, antisifilítico, coceiras, dermatoses, úlceras externas e, eczemas (SIQUEIRA, 1982; MACEDO \& FERREIRA, 2004). Até o presente momento, embora a espécie $\boldsymbol{M}$. velame seja amplamente utilizada por comunidades tradicionais que habitam o cerrado, não há relatos de um programa de conservação e utilização de uso sustentável de populações naturais da espécie. Para casos como esses, segundo AUGUSTIN et al. (2002), o desenvolvimento de protocolo de micropropagação é indicado por apresentar um potencial prático de produção em larga escala de plântulas, o que poderá evitar a erosão genética.

O objetivo deste trabalho foi desenvolver um protocolo de micropropagação de Macrosyphonia velame, com vistas à conservação da espécie em banco de germoplasma in vitro.

\section{MATERIAL E MÉTODOS}

\section{Micropropagação}

A coleta de sementes e material botânico para confecção de exsicatas foi realizada nos municípios de Sacramento, Tapira e Araxá (MG) no mês de maio de 2006, as exsicatas foram depositadas no Herbário de Plantas Medicinais da Universidade de Ribeirão Preto (Voucher HPMU-015).

As sementes foram submetidas a quatro tratamentos de assepsia: 1-24 horas em solução de cercobim $1 \%$ e logo após transferidas para álcool $70 \%$ durante 30 segundos; 2- 24 horas em solução de cercobim $1 \%+10 \mathrm{mg} \mathrm{L}^{-1}$ cefotaxima $+10 \mathrm{mg} \mathrm{L}^{-1}$ de gentamicina $+10 \mathrm{mg} \mathrm{L}^{-1}$ de canamicina, transferidas para álcool $70 \%$ por 30 segundos e, posteriormente, permaneceram 30 minutos em solução de hipoclorito de cálcio $0,5 \%$; 3-4 horas em solução de cercobim $1 \%$ + $10 \mathrm{mg} \mathrm{L}^{-1}$ de gentamicina e transferidas para uma solução de hipoclorito de cálcio $0,5 \%$, durante 30 minutos. No tratamento quatro, as sementes permaneceram 24 horas em cercobim $1 \%+10 \mathrm{mg} \mathrm{L}^{-1}$ de cefotaxima $+10 \mathrm{mg} \mathrm{L}^{-1} \mathrm{de}$ gentamicina $+10 \mathrm{~m} \mathrm{~L} \mathrm{~L}^{-1}$ de canamicina, em seguida, foram transferidas para uma solução de álcool $70 \%$ por 30 segundos e, posteriormente, permaneceram 30 minutos em hipoclorito de cálcio $1 \%$ pH 5,0. Após os tratamentos, as sementes foram lavadas em água autoclavada e inoculadas em meio Wood Plant (WP). Após 30 dias de cultivo, avaliaram-se a porcentagem de germinação e o número de sementes axênicas.

Segmentos nodais retirados de brotações axênicas advindas de sementes de M. velame germinadas in vitro foram inoculadas em meio de cultura $\mathrm{MS} / 2$, suplementado com 0,$25 ; 0,5$ e $1,0 \mathrm{mg} \mathrm{L}^{-1}$ de BAP (Benzilaminopurina), Cinetina, 2ip (Isopentenil aminopurina) e TDZ (Thidiazuron). Após 30 dias, realizaram-se avaliações quanto ao número e comprimento de broto, número de gemas por broto e presença de calos nos explantes.

Brotações mantidas em MS/2 com $6 \mathrm{~cm}$ de altura e com cinco gemas foram utilizadas no experimento de posição da gema. Foram seccionadas as gemas localizadas em quatro diferentes posições no caule (gema apical, 2ª $3^{\mathrm{a}}$ e $4^{\mathrm{a}}$ gema) e inoculadas em 
meio de cultura MS/2 suplementado com $0,5 \mathrm{mg} \mathrm{L}^{-1}$ de BAP. Os explantes foram mantidos nesse meio de cultura por 30 dias e posteriormente avaliados quanto ao número e a altura das brotações.

Brotações com $2 \mathrm{~cm}$ de comprimento foram transferidas para meios MS/2 basal e MS/2 suplementado com 1,0; 5,0 e 10,0 $\mathrm{mg} \mathrm{L}^{-1}$ de IBA (Ácido indolbutírico) ou ANA (Ácido naftalenoacético) para induzir o enraizamento. Os explantes permaneceram nos respectivos meios por 5, 10 e 30 dias, sendo, em seguida, transferidos para MS/2 isento de regulador, permanecendo por 30 dias antes da avaliação em relação à presença ou ausência de raízes.

$\mathrm{Na}$ aclimatização foram utilizadas brotações com $5 \mathrm{~cm}$ de comprimento, transferidas para sacos de polietileno preto perfurados, nas dimensões $10 \times 15 \mathrm{~cm}$, contendo como substrato: 1- solo; 2- areia; 3Plantmax $^{\circledR} ; 4$ - solo e areia (1:1); 5- solo e Plantmax ${ }^{\circledR}$ (1:1); e 6- areia e Plantmax ${ }^{\circledast}$ (1:1). Foram utilizadas 15 brotações por tratamento, as quais foram mantidas em casa de vegetação e submetidas à irrigação diária. As avaliações foram realizadas após 15, 30 e 45 dias em relação à sobrevivência das plântulas e presença ou ausência de raízes.

\section{Conservação}

Brotações mantidas em sala de crescimento com $3,5 \mathrm{~cm}$ de comprimento foram transferidas para os seguintes meios de cultura: $1-\mathrm{MS} / 2+2 \%$ de sacarose $+4 \%$ de manitol; $2-\mathrm{MS} / 2+2 \%$ de sacarose $+4 \%$ de sorbitol; $3-\mathrm{MS} / 2+2 \%$ de sacarose $+4 \%$ de manitol + $2 \mathrm{mgL}^{-1}$ de pantotenato de cálcio; $4-\mathrm{MS} / 2+2 \%$ de sacarose $+4 \%$ de sorbitol $2 \mathrm{mg} \mathrm{L}^{-1}$ de pantotenato de cálcio; $5-\mathrm{MS} / 2+2 \%$ de sacarose $+4 \%$ de manitol + $2 \mathrm{mg} \mathrm{L}^{-1}$ de espermidina; $6-\mathrm{MS} / 2+2 \%$ de sacarose + $4 \%$ de sorbitol $+2 \mathrm{mg} \mathrm{L}^{-1}$ de espermidina.

As brotações permaneceram por três meses em ambiente de Banco de Germoplasma in vitro à temperatura de $18 \pm 1^{\circ} \mathrm{C}$, fotoperíodo de 12 horas, intensidade luminosa a $25 \mathrm{mmol} \mathrm{m}^{-2} \mathrm{~s}^{-1}$ fornecida por lâmpadas do tipo fluorescente branca fria. Foram utilizadas 30 brotações por tratamento.

As análises foram realizadas em triplicata e o delineamento adotado foi o inteiramente casualizado. Os resultados foram submetidos à análise de variância e regressão através do programa SISVAR V.4.3, sendo as médias dos tratamentos comparados pelo teste de Scott-Knott $(\mathrm{P}<0,05)$.

\section{RESULTADOS E DISCUSSÃO}

Micropropagação

Sementes de M. velame submetidas ao tratamento com solução de cercobim $1 \%+10 \mathrm{mg} \mathrm{L}^{-1} \mathrm{de}$ cefotaxima, gentamicina e canamicina, por 24 horas, posteriormente imersas em solução de álcool $70 \%$ por 30 segundos, transferidas em seguida para solução de hipoclorito de cálcio $0,5 \%$ durante 30 minutos e finalmente lavadas em água autoclavada antes de serem inoculadas mostraram eficiência de descontaminação de $85 \pm 8 \%$.

Apesar do êxito na desinfestação, a porcentagem de germinação foi baixa, sendo $33 \pm 5 \%$ para sementes advindas de Araxá, $4 \pm 0,8 \%$ de Tapira e $2 \pm 0,5 \%$ de Sacramento e, além disso, a germinação foi lenta e desuniforme. Algumas sementes iniciaram a germinação após 20 dias, mas a maioria emitiu a radícula apenas 40 ou 60 dias após a inoculação. Esse resultado provavelmente está relacionado à diversidade genética do material e ou dormência da semente.

O experimento de micropropagação (Tabela 1) mostrou que os explantes de M. velame desenvolveram-se melhor em meio MS/2 sem adição de citocinina com crescimento das brotações de $5,2 \mathrm{~cm}$ de altura, produzindo 8,6 gemas por haste e menor porcentagem de vitrificação (4\%).

Estudos realizados com espécies endêmicas do Cerrado têm revelado que, de modo geral, ausência ou reduzidas concentrações de citocininas são mais adequadas para o desenvolvimento in vitro dessas espécies. Além disso, concentrações menores de reguladores de crescimento são preferidas por diminuírem as possibilidades de ocorrência de variação somaclonal e também representam menor custo (FLORES et al., 2007).

A posição da gema na haste interferiu no desenvolvimento do explante. O melhor resultado foi obtido com a gema apical que promoveu maior altura das brotações $(2,85 \mathrm{~cm})$ e maior número de gemas por haste $(6,15)$, o que possibilitou a obtenção de um maior índice de multiplicação in vitro da espécie. Trabalhos realizados como outras espécies, a exemplo de Maytenus ilicifolia e Mandevilla velutina, também mostraram a importância de se investigar a posição da gema para a obtenção de maior número de brotos por explante (PEREIRA et al., 1995; BIONDO et al., 2007).

Com relação ao enraizamento, brotações que permaneceram por 5 e 10 dias em contato com o meio de cultura suplementado com ANA ou IBA não enraizaram. Foram necessários 30 dias de exposição às auxinas para obtenção de raízes. O IBA $\left(10 \mathrm{mg} \mathrm{L}^{-1}\right)$ foi o melhor tratamento, por ter estimulado o enraizamento em $17 \%$ das plântulas, as quais apresentaram 1,5 raízes por broto. De modo geral, a presença de auxina no meio de cultura promoveu também a proliferação de calos. Segundo ANDRADE et al. (2000), a presença de calos na base do explante na fase de enraizamento não 
Tabela 1 - Efeito de diferentes concentrações e tipos de citocininas em segmento nodal de M. velame.

\begin{tabular}{|c|c|c|c|c|c|c|}
\hline Tratamentos & $\begin{array}{c}\mathrm{N}^{\mathrm{o}} \\
\text { Brotos }\end{array}$ & $\begin{array}{l}\text { № Gemas } \\
\text { por haste }\end{array}$ & $\begin{array}{l}\text { Altura } \\
(\mathrm{cm})\end{array}$ & $\%$ Necrose & $\%$ Calos & \% Vitrificação \\
\hline $\mathrm{MS} / 2$ & $4,0 \mathrm{a}$ & $8,6 a$ & $5,2 \mathrm{a}$ & $7 b$ & $4^{a}$ & $4 c$ \\
\hline $\mathrm{MS} / 2+0,25 \mathrm{mg} \mathrm{L}^{-1} \mathrm{BAP}$ & $4,4 \mathrm{a}$ & $6,3 b$ & $3,3 b$ & $10 \mathrm{~b}$ & $10 \mathrm{a}$ & $20 b$ \\
\hline $\mathrm{MS} / 2+0,50 \mathrm{mg} \mathrm{L}^{-1} \mathrm{BAP}$ & $3,8 \mathrm{a}$ & $6,2 b$ & $2,9 b$ & $27 \mathrm{a}$ & $27^{\mathrm{a}}$ & $20 b$ \\
\hline $\mathrm{MS} / 2+1,00 \mathrm{mg} \mathrm{L}^{-1} \mathrm{BAP}$ & $3,0 \mathrm{~b}$ & $3,5 \mathrm{c}$ & $1,9 \mathrm{c}$ & $44 \mathrm{a}$ & $10^{\mathrm{a}}$ & $40 \mathrm{a}$ \\
\hline $\mathrm{CV}(\%)$ & 9,54 & 15,91 & 13,30 & 14,27 & 10,94 & 11,53 \\
\hline $\mathrm{MS} / 2+0,25 \mathrm{mg} \mathrm{L}^{-1}$ Cinetina & $2,9 \mathrm{a}$ & $5,3 \mathrm{a}$ & $4,5 \mathrm{a}$ & $4 a$ & $14^{\mathrm{a}}$ & $4 c$ \\
\hline $\mathrm{MS} / 2+0,50 \mathrm{mg} \mathrm{L}^{-1}$ Cinetina & $2,8 \mathrm{a}$ & $4,6 b$ & $2,7 \mathrm{~b}$ & $14 \mathrm{a}$ & $24^{\mathrm{a}}$ & $47 \mathrm{a}$ \\
\hline $\mathrm{MS} / 2+1,00 \mathrm{mg} \mathrm{L}^{-1}$ Cinetina & $3,1 \mathrm{a}$ & $4,9 \mathrm{~b}$ & $2,6 b$ & $30 \mathrm{a}$ & $4^{\mathrm{a}}$ & $27 b$ \\
\hline $\mathrm{CV}(\%)$ & 17,69 & 23,57 & 13,20 & 23,08 & 16,19 & 11,41 \\
\hline $\mathrm{MS} / 2+0,25 \mathrm{mg} \mathrm{L}^{-1} 2 \mathrm{ip}$ & $3,4 \mathrm{a}$ & $5,9 \mathrm{a}$ & $3,5 \mathrm{a}$ & $24 \mathrm{a}$ & $40^{\mathrm{a}}$ & $7 a$ \\
\hline $\mathrm{MS} / 2+0,50 \mathrm{mg} \mathrm{L}^{-1} 2 \mathrm{ip}$ & $4,1 \mathrm{a}$ & $7,1 \mathrm{a}$ & $3,0 \mathrm{a}$ & $7 \mathrm{a}$ & $37^{\mathrm{a}}$ & $17 \mathrm{a}$ \\
\hline $\mathrm{MS} / 2+1,00 \mathrm{mg} \mathrm{L}^{-1} 2 \mathrm{ip}$ & $3,6 a$ & $6,1 \mathrm{a}$ & $3,1 \mathrm{a}$ & $10 \mathrm{a}$ & $30^{\mathrm{a}}$ & $14 \mathrm{a}$ \\
\hline $\mathrm{CV}(\%)$ & 16,22 & 20,89 & 9,59 & 14,75 & 16,61 & 10,14 \\
\hline $\mathrm{MS} / 2+0,25 \mathrm{mg} \mathrm{L}^{-1} \mathrm{TDZ}$ & $3,0 \mathrm{a}$ & $5,0 \mathrm{a}$ & $3,0 \mathrm{a}$ & $7 \mathrm{~b}$ & $27^{\mathrm{a}}$ & $30 \mathrm{a}$ \\
\hline $\mathrm{MS} / 2+0,50 \mathrm{mg} \mathrm{L}^{-1} \mathrm{TDZ}$ & $2,5 b$ & $3,8 \mathrm{~b}$ & $2,5 \mathrm{a}$ & $10 \mathrm{a}$ & $30^{\mathrm{a}}$ & $30 \mathrm{a}$ \\
\hline $\mathrm{MS} / 2+1,00 \mathrm{mg} \mathrm{L}^{-1} \mathrm{TDZ}$ & $2,1 b$ & $3,5 b$ & $2,8 \mathrm{a}$ & $27 \mathrm{a}$ & $17^{\mathrm{a}}$ & $7 \mathrm{~b}$ \\
\hline $\mathrm{CV}(\%)$ & 16,54 & 22,80 & 15,80 & 11,43 & 13,83 & 13,09 \\
\hline
\end{tabular}

Médias seguidas das mesmas letras não diferem significativamente entre si na coluna pelo teste de Scott-Knott (5\%).

é desejável, pois pode dificultar o processo de aclimatização e comprometer também o crescimento da parte aérea.

A relação concentração de auxina e tempo de exposição do explante pode ser determinante para o enraizamento in vitro (NEGASH et al., 2000). Assim, altas concentrações de auxina durante reduzido período e a transferência das plântulas para um meio livre de regulador de crescimento têm sido apontados como procedimentos adequados para o enraizamento de várias espécies cultivadas in vitro (TANTOS et al., 2001).

A aclimatização e enraizamento ex vitro apresentou maior índice de enraizamento no substrato Plantmax $^{\circledast}(40 \%)$, com 3,5 raízes por planta e média de $7,5 \mathrm{~cm}$ de comprimento.

O Plantmax ${ }^{\circledR}$ é um substrato que apresenta boa capacidade de reter água, aeração eficiente, contém significativo teor de matéria orgânica e também possui elevada porosidade (KLEIN et al., 2000). É a somatória dessas características que provavelmente facilitou a produção e maior crescimento das raízes de $\mathbf{M}$. velame .

A possibilidade de enraizamento ex vitro de M. velame é um fator importante a ser considerado no protocolo de micropropagação, pois reduz o tempo e o custo de produção, não sendo necessário à indução do enraizamento in vitro, o que torna ainda mais viável economicamente essa tecnologia para a espécie em estudo.

\section{Conservação}

Os tratamentos utilizados para obtenção de protocolo de conservação de germoplasma in vitro de M. velame responderam de maneira muito semelhante em relação à porcentagem de sobrevivência e número de brotos, entretanto o manitol foi melhor que o sorbitol para reduzir o número de gemas por haste. Embora não tenha sido registrada diferença significativa, o meio de cultura MS/2 $+2 \%$ de sacarose $+4 \%$ de manitol $+2 \mathrm{mg}$ $\mathrm{L}^{-1}$ de pantotenato de cálcio foi considerado adequado para manter plântulas de $\boldsymbol{M}$. velame em Banco de Germoplasma in vitro (Tabela 2). Os agentes osmóticos como o manitol e o sorbitol têm sido utilizados com a finalidade de alterar a disponibilidade de trocas gasosas, proteger as membranas celulares das baixas temperaturas e reduzir a hipericidade, evitando a vitrificação(ENGELMAN, 1991).

A manutenção de plântulas de $\boldsymbol{M}$. velame em banco de germoplasma in vitro é um passo importante no processo de conservação da espécie. Ao mesmo tempo, viabiliza a produção em larga escala de plantas com excelente condição fitossanitária, para atender a demanda da indústria de medicamentos fitoterápicos no Brasil.

\section{CONCLUSÃO}

É possível micropropagar M. velame em meio MS/2 basal sem o uso de reguladores vegetais e conservar plântulas da espécie em banco de 
Tabela 2 - Efeito de poliamina e agentes osmóticos na sobrevivência de explantes de M. velame mantidos em banco de germoplasma.

\begin{tabular}{|c|c|c|c|c|}
\hline Meio de cultura & $\begin{array}{c}\% \\
\text { sobrevivência }\end{array}$ & $\begin{array}{c}\text { № } \\
\text { Brotos }\end{array}$ & $\begin{array}{c}\text { № } \\
\text { Gemas }\end{array}$ & $\begin{array}{l}\text { Comprimento da } \\
\text { brotação }(\mathrm{cm})\end{array}$ \\
\hline $\mathrm{MS} / 2+2 \%$ de sacarose $+4 \%$ de manitol & $30 \mathrm{a}$ & $2,2 \mathrm{a}$ & $4,5 \mathrm{~b}$ & $2,4 \mathrm{a}$ \\
\hline $\mathrm{MS} / 2+2 \%$ de sacarose $+4 \%$ de sorbitol & $40 \mathrm{a}$ & $3,1 \mathrm{a}$ & $6,6 \mathrm{a}$ & $3,7 \mathrm{a}$ \\
\hline $\mathrm{MS} / 2+2 \%$ de sacarose $+4 \%$ de manitol $+2 \mathrm{mg} \mathrm{L}^{-1}$ de pantotenato de cálcio & $40 \mathrm{a}$ & $2,6 \mathrm{a}$ & $4,0 \mathrm{~b}$ & $2,2 \mathrm{a}$ \\
\hline $\mathrm{MS} / 2+2 \%$ de sacarose $+4 \%$ de sorbitol $2 \mathrm{mg} \mathrm{L}^{-1}$ de pantotenato de cálcio & $17 \mathrm{a}$ & $1,7 \mathrm{a}$ & $4,0 \mathrm{~b}$ & $2,1 \mathrm{a}$ \\
\hline $\mathrm{MS} / 2+2 \%$ de sacarose $+4 \%$ de manitol $+2 \mathrm{mg} \mathrm{L}^{-1}$ de espermidina & $30 \mathrm{a}$ & $1,9 \mathrm{a}$ & $4,7 \mathrm{~b}$ & $3,2 \mathrm{a}$ \\
\hline $\mathrm{MS} / 2+2 \%$ de sacarose $+4 \%$ de sorbitol $+2 \mathrm{mg} \mathrm{L}^{-1}$ de espermidina & $44 \mathrm{a}$ & $2,9 \mathrm{a}$ & $6,9 \mathrm{a}$ & $3,6 \mathrm{a}$ \\
\hline $\mathrm{CV}(\%)$ & 25,74 & 28,21 & 24,53 & 29,80 \\
\hline
\end{tabular}

Médias seguidas das mesmas letras não diferem significativamente entre si na coluna pelo teste de Scott-Knott (5\%).

germoplasma in vitro. A presença de auxina no meio de cultura é fundamental para o enraizamento in vitro de M. velame e novos estudos deverão ser realizados para otimizar o enraizamento in vitro da espécie. O enraizamento de $\boldsymbol{M}$. velame pode ser realizado ex vitro concomitantemente ao processo de aclimatização.

\section{REFERÊNCIAS}

AGUiAR, L.M.S.; CAMARGO, A.J.A. Cerrado: ecologia e caracterização. Brasília, DF: Embrapa Informação Tecnológica, 2004. 249p.

AUGUSTIN, L. et al. Micropropagação vegetal e sua importância econômica. In: BRAMMER, S.P.; IORCZESKI, E. (Eds.). Atualização em técnicas celulares e moleculares aplicadas ao melhoramento genético vegetal. Passo Fundo: Embrapa Trigo, 2002. p.135-153.

ALMEIDA, S.P. et al. Cerrado: espécies vegetais úteis. Planaltina, DF: EMBRAPA-CPAC, 1998. 464p.

ANDRADE, M.W. et al. Micropropagação da aroeira (Myracrodruon urundeuva Fr. All). Ciência e Agrotecnologia, v.24, n.1, p.174-180, 2000. Disponível em: <http://www.scielo.br/ scielo.php? script = sci_art text\&pid=S 1413 70542009000100008 >. Acesso em: 16 nov. 2010. doi: $10.1590 /$ S1413-70542009000100008.

BIONDO, R. et al. Micropropagation, seed propagation and germoplasm bank of Mandevilla velutina (Mart.). Scientia Agricola, v.64, n.3, p.263-268, 2007. Disponível em: <http:/ /www.scielo.br/pdf/sa/v64n3/08.pdf>. Acesso em: 16 nov. 2010. doi: $10.1590 / \mathrm{S} 0103-90162007000300008$.

ENGELMAN, F. In vitro conservation of tropical plant Germoplasma: a review. Euphytica, v.57, p.227-243, 1991.

FACHIM, E.; GUARIM, V.L.M.S. Conservação da biodiversidade:espécies da flora de Mato Grosso. Acta Botânica Brasileira, v.9, n.2, p.281-287, 1995.
FLORES, R. et al. Propagação clonal rápida de Pfaffia tuberosa (Spreng.) Hicken utilizando thidiazuron. Revista Brasileira Plantas Medicinais, v.9, n.1, p.1-7, 2007.

KLEIN, V.A. et al. Proprirdades físico-hídricas de substratos hortícolas comerciais. Revista Brasileira de Agrociência, v.6 n.3, p.218-221, 2000.

MACEDO, M.; FERREIRA, A.R. Plantas medicinais usadas para tratamentos dermatológiocos, em comunidades da Bacia do Alto Paraguai, Mato Grosso. Revista Brasileira de Farmacognosia, v.14, n.1, p.40-44, 2004. Disponível em: <http://www.scielo.br/pdf/rbfar/v14s0/a16v14s0.pdf>. Acesso em: 16 nov. 2010. doi: 10.1590/S0102-695X2004000300016.

MEYERS, N. et al. Biodiversity hotspots for conservation priorities. Nature, v.403, p.853-858, 2000.

NEGASH, A. et al. In vitro regeneration and micropropagation of enset from Southestern Ethiopia. Plant Cell Tissue and Organ Culture, v.62, p.153-158, 2000. Disponível em: <http://www.springerlink.com/content/w582625437487888/ fulltext.pdf $>$. Acesso em: 16 nov. 2010. doi: 10.1023/ A: 1026701419739 .

PEREIRA, A.M.S. et al. Effect of phytoregulators and physiological characteristics of the explants on micropropagation of Maytenus ilicifolia. Plant Cell, Tissue and Organ Culture, v.42, p.295-297, 1995. Disponível em: <http://www.springerlink.com/content/w1361250r5004222/ fulltext.pdf $>$. Acesso em: 16 nov. 2010. doi: 10.1007/ BF00030003.

SIQUEIRA, J.C. Plantas do cerrado na medicina popular. Jornal Brasileiro de Ciência, v.2, n.8, p.41-44, 1982.

TANTOS, A. et al. Triacontanol-sipported micropropagation of woody plants. Plant Cell reports, v.20, p.16-21, 2001. Disponível em: <http://www.springerlink.com/content/ 3dyd43106pf9em8m/fulltext.pdf $>$. Acesso em: 16 nov. 2010. doi: $10.1007 / \mathrm{s} 002990000282$. 